\title{
Pain in patients attended at risk classification of an emergency service
}

\author{
Dor em pacientes atendidos na classificação de risco de um serviço de urgência
}

Jamille Santos da Silva', Taynara Apolonia Fagundes da Cruz¹, Caíque Jordan Nunes Ribeiro', Victor Santana Santos², José Antonio Barreto Alves $^{3}$, Maria do Carmo de Oliveira Ribeiro ${ }^{3}$

\section{ABSTRACT}

BACKGROUND AND OBJECTIVES: Pain is a major symptom responsible for the search for urgency care. This study aimed at checking the presence of pain in patients attending the risk classification.

METHODS: This is a cross-sectional and descriptive study carried out at an urgency care unit, using a form with socio-demographic and clinical data, risk classification, analgesia and pain record on medical charts. Pain Management Index proposed by the World Health Organization was calculated.

RESULTS: From 102 patients included in the study, 82 (80.2\%) reported pain, $45(54.9 \%)$ were females, 48 (58.5\%) were married, most (62 - 75.6\%) lived in Greater Aracaju, 28 (34.1\%) were classified as yellow. Acute, severe to moderate pain was the most frequent. In $71(86.6 \%)$ cases, continuous pain has motivated the search for urgency care. Pain recording was present in almost all medical charts, being $80.5 \%$ performed by physicians. Simple analgesics and non-steroid anti-inflammatory drugs were the most frequently prescribed analgesics $(59-72 \%)$. Pain management was inadequate in $86.6 \%$ of cases and there has been wide variation between admission and administration of first analgesia (mean: $94.5 \mathrm{~min}$; min-max: 8-360 min).

CONCLUSION: The lack of analgesic protocols at risk classification may impair adequate pain management.

Keywords: Nursing at emergency, Pain, Pain Measurement, Screening.

\section{RESUMO}

JUSTIFICATIVA E OBJETIVOS: A dor é um dos principais sintomas responsáveis pela procura de serviços de urgência. $\mathrm{O}$ objetivo deste estudo foi verificar a presença de dor em pacientes atendidos na classificação de risco.

1. Universidade Federal de Sergipe, Departamento de Enfermagem, Aracaju, SE, Brasil. 2. Universidade Federal de Sergipe, Programa de Pós-Graduação em Ciências da Saúde, Aracaju, SE, Brasil.

3. Universidade Federal de Sergipe, Aracaju, SE, Brasil.

Submitted in October 26, 2015.

Accepted for publication in January 21, 2016.

Conflict of interests: none - Sponsoring sources: none.

Correspondence to:

Maria do Carmo de Oliveira Ribeiro

Av. Cláudio Batista, S/N - Bairro Sanatório

49060-108 Aracaju, SE, Brasil.

E-mail: enffer2@gmail.com

(C) Sociedade Brasileira para o Estudo da Dor
MÉTODOS: Estudo transversal e descritivo, realizado em um serviço de urgência. Foi utilizado formulário que continha os dados sócio-demográficos e clínicos, classificação de risco, analgesia e registro da dor em prontuário. Foi calculado o Índice de Manuseio da Dor proposto pela Organização Mundial de Saúde. RESULTADOS: Dos 102 pacientes incluídos no estudo, 82 $(80,2 \%)$ relataram dor, $45(54,9 \%)$ eram do gênero feminino, $48(58,5 \%)$ eram casados, a maioria $(62-75,6 \%)$ residentes da grande Aracaju, 28 (34,1\%) foram classificados como amarelo. A dor aguda, intensa à moderada foi a mais frequente. Em 71 $(86,6 \%)$ casos, a dor do tipo continua motivou a procura pelo serviço de urgência. $\mathrm{O}$ registro de dor esteve presente na quase totalidade dos prontuários, sendo $80,5 \%$ realizados pelos médicos. Os analgésicos simples e anti-inflamatórios não esteroides foram os mais prescritos $(59-72 \%)$. O manuseio da dor foi inadequado em $86,6 \%$ dos casos e existiu grande variação entre o tempo de admissão e administração da primeira analgesia (média: 94,5min; mín-máx: 8-360min).

CONCLUSÁO: A ausência de protocolos de analgesia na classificação de risco pode dificultar o adequado manuseio do fenômeno doloroso.

Descritores: Dor, Enfermagem em emergência, Mensuração da dor, Triagem.

\section{INTRODUCTION}

The search for urgency assistance has increased and most patients report pain at screening. As from this complaint, resources are used to classify and organize patients' priorities. Pain is a major reason for human suffering, brings incapacities which reflect on quality of life (QL) and generate major psychosocial and economic repercussions ${ }^{1}$.

Defined as unpleasant sensory and emotional experience, pain is associated to real or potential tissue injury, or is described in terms of such injury ${ }^{2}$. So, it is visible the need to measure pain from patients' arrival to the urgency unit until their hospital discharge.

Pain is common in patients looking for urgency services. A study evaluating pain in trauma victims has identified it in $90 \%$ of cases $^{3}$. So, there is a real need for adequate pain management in this group of patients, aiming at offering better assistance, thus assuring that recommendations of the International Association for the Study of Pain (IASP) and of the Single Health System (SUS) are followed.

In Brazil, the National Humanization Policy (NHP), created by the Department of Health in $2003^{4}$, establishes assistance with risk classification to provide SUS users a holistic, friend- 
ly and humanized assistance.

Health services have adopted the Manchester Protocol to organize queues in urgency services. This protocol is built with categories of signs and symptoms and not with pre-established urgency scales. As from clinical data (signs and symptoms), individuals are classified by colors (red, orange, yellow, green and blue) and service time is established according to severity 5 . Pain during screening associated to other signs and symptoms, orients patients' classification according to the protocol of the service.

This study aimed at observing the presence of pain, its characteristics and management among patients seen by the risk classification of the most important urgency service of Sergipe. This study was justified by the need to understand the profile of the public seen by the risk classification, especially with regard to pain as motivating symptom for the search for urgency services.

\section{METHODS}

This is a cross-sectional, descriptive and exploratory study with 102 patients seen by the risk classification from March to April 2015, in the most important public urgency hospital of Sergipe-Brazil, located in the city of Aracaju, capital of the state. This hospital is reference for urgency and emergency services for the whole state of Sergipe and is responsible for approximately 250 weekly consultations. So, to estimate sample size, we considered an expected proportion that $30 \%$ of patients look for health services due to pain. With this parameter, and considering $95 \%$ confidence interval and power of 80 , sample was estimated in 102 patients.

Inclusion criteria were age above 18 years and cognitive conditions to answer questions. Exclusion criteria were unstable patients, hemodynamic instability and being victim of trauma. Initially a pilot test was carried out with seven patients to gage data collection tool and researchers. These seven patients were excluded from the final sample.

Data were collected after evaluation by risk classification and by the physician on duty. Patients meeting inclusion criteria were invited to participate in the research. After signing the Free and Informed Consent Term (FICT), patients were interviewed by trained research assistants and documental analysis of medical charts was carried out by researchers.

A structured questionnaire was used for data collection with the following information: socio-demographic and clinical data, risk classification, previously used analgesia and analgesia during urgency assistance, pain presence, intensity and duration, its periodicity, location, improving and worsening factors, and pain record on medical charts.

Pain was measured with the numeric scales where zero corresponds to no pain and 10 to maximum pain ${ }^{2}$. Patients were asked to verbally state the value corresponding to their pain. To evaluate pain management according to World Health Organization (WHO) recommendations ${ }^{6}$, Pain Management Index (PMI) was calculated. This index takes into ac- count the analgesic drug prescribed and pain intensity referred by patients, and is established as follows: analgesic potency is subtracted from pain intensity referred by patient. PMI varies from -3 to +3 ; negative scores point to the use of inadequate analgesics and zero or positive scores indicate adequate analgesia ${ }^{6}$. Analgesics were classified according to their analgesic potency (AP), where zero means no analgesic drug; 1 - non-steroid anti-inflammatory drug (NSAID); 2 - weak opioid; 3 - strong opioid. Pain intensity (PI) was classified as zero - no pain, 1 - mild pain (1-4), 2 moderate pain $(5-7)$ and 3 - severe pain $(8-10)^{7}$.

\section{Statistical analysis}

Information was coded and inserted in a database. Then data were submitted to exploratory analysis. Categorical variables were described with absolute and percentage frequencies. Kolmogorov-Smirnov test was used to check normality (symmetry) of numerical variables distribution. Since distribution was asymmetric, non-parametric Mann-Whitney test was used. Chi-square test or Fisher Exact test were used to evaluate the association of patients' profile and the presence of pain during evaluation. Statistical significance was $5 \%(p<0.05)$. Data were analyzed by the software Statistical Package for the Social Sciences (SPSS) version 20.0 and are shown in tables.

Recommendations of Resolution 466/2010, of the National Health Council were followed in all research stages.

The study was approved by the Ethics Committee, Universidade Federal de Sergipe, CAAE 40884415.0.0000.5546.

\section{RESULTS}

A total of 102 patients were eligible for the study. However, one participant was excluded for being less than 18 years old. Among respondents, 19 (18.8\%) have not reported pain. Final sample was made up of $82(80.2 \%$ patients with median age (interquartile interval, IIQ) of 36 years (27-49), of whom $54.9 \%$ were females, $58.5 \%$ were married, $75.6 \%$ lived in greater Aracaju, $43.9 \%$ had basic education and $34.1 \%$ were classified as yellow risk (Table 1 ).

Sample was considered homogeneous for socio-demographic characteristics since there were no statistically significant differences among patients reporting or not pain at risk classification (Table 1). However, patients referring pain were younger than those without pain $(p=0.027$, Mann-Whitney test).

Study results have shown that patients had mean (standard deviation) pain of 7.4 (2.8), being acute in $95.1 \%$ of patients, severe and moderate in $53.7 \%$ and $36.6 \%$, respectively. Pain was continuous in $56.1 \%$ of cases and in $86.6 \%$ it was associated to major reason for looking for the urgency service. Rest and change in position were improving and worsening factors and abdominal region was the most frequent site of pain $(32.9 \%)$. Almost all medical charts had pain record $(95.1 \%)$ being that in $80.5 \%$ of cases records were filled by physicians (Table 2). 
Table 1. Socio-demographic and clinical characterization of users seen by the risk classification sector of an urgency service. Aracaju, SE, Brazil, 2015

\begin{tabular}{|c|c|c|c|c|c|}
\hline \multirow[t]{3}{*}{ Variables } & \multicolumn{4}{|c|}{ Pain } & \multirow[t]{3}{*}{$p$ value } \\
\hline & \multicolumn{2}{|c|}{ Yes } & \multicolumn{2}{|c|}{ No } & \\
\hline & $\mathrm{n}$ & $\%$ & $\mathrm{n}$ & $\%$ & \\
\hline \multicolumn{6}{|l|}{ Gender } \\
\hline Female & 45 & 54.9 & 9 & 47.4 & $0.529^{*}$ \\
\hline Male & 37 & 45.1 & 10 & 52.6 & \\
\hline \multicolumn{6}{|l|}{ Marital status } \\
\hline Married & 48 & 58.5 & 12 & 63.2 & $0.511^{* *}$ \\
\hline Single & 26 & 31.7 & 4 & 21.0 & \\
\hline Divorced & 6 & 7.3 & 1 & 5.3 & \\
\hline Widow/er & 2 & 2.5 & 2 & 10.6 & \\
\hline \multicolumn{6}{|l|}{ Place of residence } \\
\hline Greater Aracaju & 62 & 75.6 & 10 & 52.6 & $0.106^{* *}$ \\
\hline Interland of Sergipe & 19 & 23.2 & 8 & 42.1 & \\
\hline Different state & 1 & 1.2 & 1 & 5.3 & \\
\hline \multicolumn{6}{|l|}{ Education level } \\
\hline Illiterate & 11 & 13.4 & 5 & 26.3 & $0.426^{* *}$ \\
\hline Basic & 36 & 43.9 & 9 & 47.4 & \\
\hline High school & 30 & 36.6 & 4 & 21.0 & \\
\hline College & 5 & 6.1 & 1 & 5.3 & \\
\hline \multicolumn{6}{|l|}{ Origin } \\
\hline Home & 46 & 56.1 & 9 & 47.4 & $0.609^{* *}$ \\
\hline Health services & 27 & 11.0 & 7 & 36.8 & \\
\hline Others & 9 & 32.9 & 3 & 15.8 & \\
\hline \multicolumn{6}{|l|}{ Risk classification } \\
\hline Red & 1 & 1.2 & 0 & 0 & $0.894^{* *}$ \\
\hline Orange & 11 & 13.5 & 2 & 10.6 & \\
\hline Yellow & 28 & 34.1 & 8 & 42.1 & \\
\hline Green & 25 & 30.5 & 4 & 21.0 & \\
\hline Blue & 1 & 1.2 & 0 & 0 & \\
\hline Not classified & 16 & 19.5 & 5 & 26.3 & \\
\hline
\end{tabular}

"Fisher Exact test; "Chi-square test.

Table 2. Pain evaluation of users seen by the risk classification sector of an urgency service. Aracaju, SE, Brazil, 2015

\begin{tabular}{lccc}
\hline Variables & $\mathrm{n}$ & $\%$ & $\mathrm{p} \mathrm{value}^{\dagger}$ \\
\hline Major reason related to pain & & & \\
$\quad$ Yes & 71 & 86.6 & $<0.001$ \\
$\quad$ No & 11 & 13.4 & \\
Pain duration & & & \\
$\quad$ Acute & 48 & 95.1 & $<0.001$ \\
$\quad$ Chronic & 4 & 4.9 & \\
Pain intensity & & & \\
$\quad$ Mild $(1-4)$ & 44 & 53.7 & $<0.001$ \\
$\quad$ Moderate $(5-7)$ & 30 & 36.5 & \\
$\quad$ Severe $(8-10)$ & 8 & 9.8 & \\
\hline
\end{tabular}

Table 2. Pain evaluation of users seen by the risk classification sector of an urgency service. Aracaju, SE, Brazil, 2015 - continuation

\begin{tabular}{|c|c|c|c|}
\hline Variables & $\mathrm{n}$ & $\%$ & $p$ value $^{\dagger}$ \\
\hline \multicolumn{4}{|l|}{ Pain characteristic } \\
\hline Intermittent & 34 & 44.5 & \\
\hline Continuous & 46 & 56.1 & 0.21 \\
\hline \multicolumn{4}{|l|}{ Fimproving factors } \\
\hline Rest & 26 & 31.7 & 0.004 \\
\hline Change in position & 9 & 11.0 & \\
\hline Does not know & 30 & 36.6 & \\
\hline Others & 17 & 20.7 & \\
\hline \multicolumn{4}{|l|}{ Worsening factors } \\
\hline Change in position & 30 & 36.6 & 0.79 \\
\hline Does not know & 27 & 32.9 & \\
\hline Others & 25 & 30.5 & \\
\hline \multicolumn{4}{|l|}{ Pain location } \\
\hline Head & 11 & 13.4 & $<0.001$ \\
\hline Chest & 6 & 7.3 & \\
\hline Abdomen & 27 & 32.9 & \\
\hline Extremities & 7 & 8.6 & \\
\hline Multiple & 21 & 25.6 & \\
\hline Others & 10 & 12.2 & \\
\hline \multicolumn{4}{|l|}{ Pain record } \\
\hline Yes & 78 & 95.1 & $<0.001$ \\
\hline No & 4 & 4.9 & \\
\hline \multicolumn{4}{|c|}{ Professional in charge of recording } \\
\hline Physicians & 66 & 80.5 & 0.16 \\
\hline Nurses & 56 & 68.3 & \\
\hline
\end{tabular}

${ }^{\dagger}$ Adherence Chi-square value with Yates correction.

Our study has identified that $46.3 \%$ of patients used analgesia without medical prescription before looking for the urgency service. From them, $4.9 \%$ did not know the drug used; $26.8 \%$ stated using simple analgesics and/or NSAIDS; and $14.6 \%$ stated using antispasmodic or muscle relaxants alone or associated to NSAIDS (Table 3).

In almost all cases, analgesics were prescribed by emergency physicians (97.6\%), being simple analgesic and NSAIDS the most commonly prescribed drugs in $72 \%$ of cases, thus characterizing the practice of oligoanalgesia (Table 3).

Although pain being classified as moderate to severe, administered analgesia was not adequate to relieve pain in $86.6 \%$ of cases. Mean time between admission to the urgency service and administration of analgesia was 94.5 (50.7-172) minutes; minimum time was eight minutes and maximum time was 360 minutes (Table 4). 
Table 3. Analgesic consumption in an urgency public service. Aracaju, SE, Brazil, 2015

\begin{tabular}{|c|c|c|c|}
\hline Variables & $\mathrm{n}$ & $\%$ & $p$ value \\
\hline \multicolumn{4}{|l|}{ Previous use of analgesia } \\
\hline Yes & 38 & 46.3 & $<0.001$ \\
\hline No & 44 & 53.7 & \\
\hline \multicolumn{4}{|l|}{ Previously used analgesic } \\
\hline Simple analgesic or NSAIDS & 19 & 23.2 & $<0.001$ \\
\hline Buscopan & 7 & 8.5 & \\
\hline Simple analgesic + NSAIDS㧊 & 6 & 7.3 & \\
\hline Muscle relaxant & 2 & 2.4 & \\
\hline Does not know & 4 & 4.9 & \\
\hline Did not use & 44 & 53.7 & \\
\hline \multicolumn{4}{|l|}{ Received analgesia in the service } \\
\hline Yes & 80 & 97.6 & $<0.001$ \\
\hline No & 2 & 2.4 & \\
\hline \multicolumn{4}{|l|}{ Analgesic received in the service } \\
\hline Simple analgesic + NSAIDS㧊 & 59 & 72.0 & $<0.001$ \\
\hline Weak opioid & 16 & 19.5 & \\
\hline Simple analgesic + weak opioid & 4 & 4.9 & \\
\hline Strong opioid & 1 & 1.2 & \\
\hline Has not received analgesia & 2 & 2.4 & \\
\hline \multicolumn{4}{|l|}{ Administration route } \\
\hline Intravenous & 66 & 80.5 & $<0.001$ \\
\hline Venous + muscular & 11 & 13.4 & \\
\hline Other route associations & 3 & 3.7 & \\
\hline Has not received analgesia & 2 & 2.4 & \\
\hline
\end{tabular}

Table 4. Adequacy of analgesic treatment and time between admission and first analgesia in an urgency service. Aracaju, SE, Brazil, 2015

\begin{tabular}{lccc}
\hline Variables & $\mathrm{n}$ & $\%$ & value $^{\S}$ \\
\hline Adequate analgesic treatment & & & \\
$\quad$ Yes & 11 & 13.4 & $<0.001$ \\
$\quad$ No & 71 & 86.6 & \\
Time between admission and $1^{\text {st }}$ anal- & & & \\
gesia (min) & & & \\
$1-10$ & 2 & 2.4 & $<0.001$ \\
$11-60$ & 23 & 28.1 & \\
$61-120$ & 25 & 30.5 & \\
$121-240$ & 21 & 25.6 & \\
$>240$ & 11 & 13.4 & \\
\$Adherence Chi-square value with Yates correction. & & \\
& & & \\
& &
\end{tabular}

sAdherence Chi-square value with Yates correction.

\section{DISCUSSION}

Pain is a common symptom in urgency services, especially in risk classification, which requires effective strategies for its relief. So, deleterious effects caused by untreated pain should be avoided, thus providing patients with assistance based on ethics and humanization.
Most patients of our study were females. Studies ${ }^{8,9}$ evaluating pain in emergency services have found similar results. It is believed that females are more concerned with health, thus looking more often for medical assistance, as shown in our study.

There has been prevalence of patients with complete or incomplete basic education. A study emphasizes that people with lower education levels have less perspective to satisfactorily deal with pain ${ }^{10}$. Poor education level, associated to unfavorable socioeconomic conditions, may impair the understanding of health primary and tertiary attention functions. So, the lack of knowledge of the real function of the urgency service overloads the tertiary attention, increases waiting time and patients dissatisfaction, thus changing logistics of such services.

As to risk classification, approximately one third of patients were classified as yellow. A study aiming at checking the level of agreement between institutional and Manchester protocols has found different results ${ }^{5}$. These researchers have identified patients classified as red and orange. According to the Manchester protocol ${ }^{11}$, patients are classified according to severity in red (imminent risk of death), orange (very urgent), yellow (without imminence of death), green (moderate risk) and blue (low risk). The higher frequency of patients classified as yellow is related to the fact that, in the studied service, patients with imminent risk of death are directly referred to the red area of the first aid unit.

Almost all patients have referred acute pain. A study ${ }^{12}$ identifying pain in the postoperative period of craniotomy has shown data similar to ours. Acute pain may change blood pressure, temperature and heart rate, and may decrease oxygen tissue supply and impair daily life activities.

Severe to moderate continuous pain was the most frequent, as opposed to a study carried out in the USA evaluating pain management in the emergency service ${ }^{13}$. Severe pain leads to physical and emotional distress not only to patients but also to relatives. In addition, continuous pain is characterized for being sudden and spontaneous or related to a certain activity. So, adequate pain management is critical to provide comfort to patients, to avoid negative effects of untreated pain, pain recurrence, as well as frequent returns to urgency services.

Pain was associated to the major reason for looking for urgency services in most cases, being abdominal the most frequent pain. This result differs from a study which has observed back pain as the predominant type ${ }^{14}$. Lumbar and abdominal pain impairs production and productivity, in addition to affecting patients' QL.

Factors improving and worsening pain were, respectively, rest and change in position. Health professionals have several methods to manage pain, among them, pharmacological and non-pharmacological therapies. So, they should use all available resources aiming at promoting pain relief, thus improving satisfaction of users looking for health services.

There has been inadequate analgesia in this study since in spite of severe pain in most cases, simple analgesics and NSAIDS were the most commonly prescribed drugs, which 
characterizes the practice of oligoanalgesia. These data confirm a study carried out in a teaching hospital of the USA ${ }^{15}$. It was also possible to observe the low cost of strong opioids, which are highly recommended for severe pain ${ }^{16}$. Although a wide availability of opioids in the market, simple analgesics and NSAIDS prescription is still a common practice in urgency services.

With regard to time between admission and first analgesia in the urgency service, there has been a delay, in some cases, for the administration of the first analgesia. These results confirm a study where researchers have observed mean time of 90 minutes $^{13}$, which shows that urgency services overload is a common problem also in other countries.

Additionally, according to the Manchester protocol ${ }^{11}$, patients classified as yellow should be assisted no longer than in 60 minutes. In our study, although almost one third of patients being classified this way, $69.5 \%$ of patients were seen in a period above that recommended. Overcrowding of urgency services, added to the lack of analgesia protocols and organization of patients flow, may contribute for the delay in starting treatment and receiving analgesia, in addition to increasing risks for negative outcomes.

Pain records were mostly filled by physicians, however there were no medical chart specifications about pain characteristics. On the other hand, the study ${ }^{12}$ has identified that most medical charts had no records about pain by the multiprofessional team and, when existing, they were performed by physicians. In a study carried out in Turkey, just $35.1 \%$ of nurses reported keeping pain records in all medical charts ${ }^{17}$. Adequate and complete pain record on medical charts is a major tool to guide therapeutic approach and evaluation of its efficacy, especially for nursing professionals, aiming at assuring ethic-legal support.

\section{CONCLUSION}

The study about pain in patients seen by the risk classification of an urgency service has enabled the following conclusions: females were predominant and most patients were young adults; major reason for looking for the urgency service was related to pain; rest and change in position were pain improving and worsening factors, respectively. Some patients were classified as yellow and pain was described as acute, continu- ous, from severe to moderate, however there has been inadequate management. Physicians were professionals more often recording pain on medical charts, however its characteristics were absent.

In light of the above, some questions are raised: why are there no analgesia protocols in risk classification? Why is there a large number of patients choosing urgency services rather than looking for primary attention? Why is oligoanalgesia still a frequent practice? Answers to these questions are complex and need further studies trying to solve such issues.

\section{REFERENCES}

1. Sousa FA, Pereira LV, Cardoso R, Hortense P. Multidimensional pain evaluation scale Rev Lat Am Enfermagem. 2010;18(1):3-10.

2. International Association for Study of Pain (IASP). Consensus development conference statement: the integrated approach to the management of pain. Accid Emerg Med. 1994;6:491-2.

3. Calil AM, Pimenta CA, Birolini D. The "oligoanalgesia problem" in the emergency care. Clinics. 2007;62(5):591-8.

4. Ministério da Saúde (BR). Política Nacional de Humanização. Formação e intervenção. [internet]. 1st ed. Brasília (BR): Ministério da Saúde; 2010. [acesso em: 15 maio 2015]. Disponível em: <http://bvsms.saude.gov.br/bvs/publicacoes/cadernos_humanizaSUS.pdf>.

5. Souza CC, Toledo AD, Tadeu LF, Chianca TC. Risk classification in an emergency room: agreement level between a Brazilian institutional and the Manchester Protocol. Rev Lat Am Enfermagem. 2011;19(1):26-33.

6. World Health Organization. Cancer pain relief with a guide to opioid availability, $2^{\text {nd }}$ ed. Geneva: WHO; 1996.

7. Calil AM, Pimenta CA. [Pain intensity of pain and adequacy of analgesia]. Rev Lat Am Enfermagem. 2005;13(5):692-9. Portuguese.

8. Oliveira GN, Silva MF, Araujo IE, Carvalho-Filho MA. Profile of the population cared for in a referral emergency unit. Rev Latino Am Enfermagem. 2011;19(3):548-56.

9. Wheeler E, Hardie T, Klemm P, Akanji I, Schonewolf E, Scott J, et al. Level of pain and waiting time in the emergency department. Pain Manag Nurs. 2010;11(2):10814.

10. Joynt M, Train MK, Robbins BW, Halterman JS, Caiola E, Fortuna RJ. The impact of neighborhood socioeconomic status and race on the prescribing of opioids in emergency departments throughout the United States. J Gen Intern Med. 2015;28(12):1604-10.

11. van der Wulp I, Sturms LM, de Jong A, Schot-Balfoort M, Schrijvers AJ, van Stel HF Pain assessments at triage with the Manchester triage system: a prospective observational study. Emerg Med J. 2011;28(7):585-9.

12. de Oliveira Ribeiro Mdo C, Pereira CU, Sallum AM, Martins-Filho PR, Desantana JM, da Silva Nunes M, et al. Immediate post-craniotomy headache. Cephalalgia. 2013;33(11):897-905.

13. Tood KH, Ducharme J, Choiniere M, Crandall CS, Fosnocht DE, Homel P, et al Pain in the emergency department: results of the pain and emergency medicine initiative (PEMI) multicenter study. J Pain. 2007;8(6):460-6.

14. Langley PC. The prevalence, correlates and treatment of pain in the European Union. Curr Med Res Opin. 2011;27(2):463-80.

15. Cordell WH, Keene KK, Giles BK, Jones JB, Jones JH, Brizendine EJ. The high prevalence of pain in emergency medical care. Am J Emerg Med. 2002;20(3):165-9.

16. Calil AM, Pimenta CA. Importance of pain evaluation and standardization of analgesic medication in emergency services. Acta Paul Enferm. 2010;23(1):53-9.

17. Ucuzal M, Dogãn R. Emergency nurses' knowledge, attitude and clinical decision making skills about pain. Int Emerg Nurs. 2015;23(2):75-80. 